\title{
DIRECTIONALLY RECRYSTALLIZED TD NiCr
}

R. E. Allen, Mgr., Powder Metallurgical Alloys

General Electric Company

Cincinnati, Ohio - 45215

Abstract

A solid state crystal growing process named ZAP (Zone Aligned Polycrystals) has been developed which is capable of producing either columnar oriented crystals or monocrystals from as-extruded TD NiCr. Stress rupture testing of columnar grained bars in which the (001) planes are perpendicular to the stress axis indicate that this material is approximately twice as strong as the same as-extruded product given a conventional recrystallization heat treatment.

Specimens from three different mill shapes were successfully ZAP processed: extruded round bar, extruded sheet bar, and sheet. ZAP process rates increase with increasing recrystallization temperatures and the maximum rate achievable is therefore dependent upon prior processing. Stress rupture ductilities in round bar are also improved by ZAP processing; i. e., 6-7\% elongation vs 1-2\% in conventionally processed bar. Although the majority of the work has been conducted on TD NiCr, the process is also applicable to other dispersion strengthened alloys.

\section{Introduction}

Oxide dispersion strengthened (ODS) alloys are normally used in one of two possible microstructural conditions - in the as-worked "unrecrystallized" condition or in the as-worked plus "recrystallized" condition. SAP (Sintered Aluminum Powder) and TDNi bar are examples of the former while TD NiCr, TD Co, and TD MCrAlY alloys are examples of the latter. Wilcox and Clauer( 1 , 2$)$ evaluated TDNi bar microstructure and found that the best properties were achieved with a fine needle shaped grain structure which was very resistant to recrystallization even at temperatures approaching the melting point. High temperature strength was found to be proportional to the length to diameter ratio of the grains. Alloys with lower stacking fault energies such as TD NiCr, TD Co and TD MCrAlY are normally used in the recrystallized condition. Mincher et $\mathrm{al}^{(3)}$ showed that the properties of TD Co alloys, (which are used after recrystallizing) depended on grain size, and that $2000 \mathrm{~F}$ rupture life obeyed the empirical relationship: $L=K^{n}$, where $L$ is life, $K$ and $n$ are constants and d is grain size. This relationship was found to apply to ODS FeCrAlY alloys also, and Allen(4) reported a value of 1.5 for $n$, compared to an $n$ of 2.5 found by Mincher for TDCo. On the basis of this relationship, maximum properties achievable for this material should be associated with monocrystals. Increases in grain size have normally been sought by varying the thermomechanical processing (TMP) parameters which in turn varies the as-worked substructure and ultimately, the recrystallized grain size. TMP produces anisotropy in the as-worked microstructure which may enhance high temperature properties. If the alloy is used in the as-worked condition, the anisotropy may take the form of a strong deformation texture and elongated grains or subgrains, as in TDNi(5). High temperature strength was reported in this case to be directly proportional to the length to diameter ratio of the grains produced by TMP. In alloys which are used in the "recrystallized" condition, the anisotropy produced during TMP causes directional effects in grain boundary mobility. As a result, grain growth is much more rapid in ccrtain directions and large irregularly shaped grains are formed. TD NiCr sheet, for example, forms pancake shaped grains during recrystallization. 
Both of these observations suggest that high temperature properties would be enhanced if monocrystals or large columnar grains could be produced in oxide dispersion strengthened (ODS) alloys. In an effort to capitalize on this observation, a study of directional recrystallization in $\mathrm{TD} \mathrm{NiCr}$ was undertaken. As a result of this study, a solid state crystal growing technique has been developed which is capable of producing either columnar oriented crystals or monocrystals in several differcnt alloys. This process has been given the acronym ZAP (Zone Aligned Polycrystals) and had been successfully applied to TD NiCr, TD NiCrAlFeY, ODS FeCrAlY, powder metallurgy (PM) Rene' 77, PM modified Rene' 95, and PM Rene' 80. In oxide dispersion strengthened alloys, the influence of such changes in microstructure on mechanical properties is quite large. In the PM alloys without intentional oxide addition, strength changes are less spectacular but are nevertheless achievable by the ZAP process. The greatly increased strength of TD NiCr as a result of ZAP is of major interest and will be reported here in greater detail.

\section{Starting Material}

Small specimens from four different $\mathrm{TD}$ NiCr mill products were processed - sheet, extruded round bar, extruded sheet bar, and extruded airfoil shapes. None of the materials were prepared especially for ZAP processing but were selected from existing material. Selection was made based on the fact that all of the materials were available in the unrecryslallized condilion, which is a requisite for the ZAP process. Nominal chemistry, dimensions and approximate working temperature of the starting materials which were prepared by Fansteel are given in Table $I$. None of these alloys was heat treated prior to ZAP processing.

All of the alloys contain contaminant oxygen in the form of $\mathrm{Cr}_{2} \mathrm{O}_{3}$. The size and morphology of this phase was a function of metal working history, particularly the amount and difection of plastic deformation. Extruded sheet bar from TC3200 received the smallest amount of plastic deformation of the four alloys studied and as a result, the $\mathrm{Cr}_{2} \mathrm{O}_{3}$ particles were large and only slightly elongated in the direction of extrusion. Higher reduction ratios during extrusion, as in the small diameter bar, fragmented these large $\mathrm{Cr}_{2} \mathrm{O}_{3}$ and elongated them in the direction of extrusion, producing line imperfections. Sheet material received the largest plastic deformation and therefore contained the smallest size distribution of $\mathrm{Cr}_{2} \mathrm{O}_{3}$. Spatial distribution in sheet was planar as a result of the planar mode of deformation. These differences may be seen in the photomicrographs of Figure 1. Metal working has created a definite anisotropy in $\mathrm{Cr}_{2} \mathrm{O}_{3}$ distribution.

In some instances, additional anisotropy in starting material may result from a deformation texture produced during TMP. Laue transmission photographs of three of the four starting materials, shown in Figure 2, were taken in an effort to determine the presence of such a texture in these materials. Sheet material (TC3085-1) and small diameter bar (TC2758-1) show very faint indications of a texture but the asextruded sheet bar (TC3200) has no apparent crystallograph1c an1sotropy.

Electron transmission microscopy of sheet (TC3085-1) and sma11 diameter bar (TC2758-1) was conducted in order to show differences in substructure between these two starting materials. As may be seen in Figure 3 , the sheet has a finer cell size and a much higher density of free dislocations than the small diameter bar. This difference is also reflected by recrystallization behavior, since the sheet recrystallizes at approximately $1650 \mathrm{~F}$ and the small diameter bar at $2250 \mathrm{~F}$. 
TABLE I

STARTING MATERIALS FOR ZAP PROCESS STUDIES

$\begin{array}{llc}\text { Designation } & \text { Nominal Chemistry } & \text { Form } \\ \text { TC3584 } & \text { Ni-20Cr-2ThO } & 1.25^{\prime \prime} \times 5.75^{\prime \prime} \text { Sheet Bar } \\ \text { TC2758-1 } & \mathrm{Ni}-20 \mathrm{Cr}-2 \mathrm{ThO}_{2} & .236^{\prime \prime} \mathrm{dia} . \mathrm{Bar} \\ \mathrm{TC} 3085-1 & \mathrm{Ni}-20 \mathrm{Cr}-2 \mathrm{ThO}_{2} & .060^{\prime \prime} \text { Sheet } \\ \text { TC3200 } & \mathrm{Ni}-20 \mathrm{Cr}-2 \mathrm{ThO}_{2} & 1^{\prime \prime} \times 1^{\prime \prime} \times 6^{\prime \prime} \\ \mathrm{TC} 2760-1 \mathrm{~B} & \mathrm{Ni}-20 \mathrm{Cr}-2 \mathrm{ThO}_{2} & .235^{\prime \prime} \mathrm{dia} . \mathrm{Bar}\end{array}$

Extrusion Parameters

1750F Sinter $1750 F$ Breakdown $8^{\prime \prime} \rightarrow 1.25^{\prime \prime} x$ (Canned)

Upset Billet $(1750 F)+1860 F / 162 \times$ Bare

Rolling Temperature 1300F (Approximate)

Unknown

Extruded Bare - Conditions Unknown 
In preparation for ZAP processing, specimens $1 / 4$ in. diameter were machined from the sheet bar and the airfoil. The .235 in. diameter bar was degreased and macroetched lightly before ZAP processing. Specimens $1 / 2$ in. wide by sheet thickness (.060 in.) were used for the sheet specimen. All specimens were macroetched in $\mathrm{HNO}_{3}+\mathrm{H}_{2} \mathrm{O}_{2}$ hefore ZAP processing.

\section{ZAP PROCESS EQUIPMENT REQUIREMENTS}

The ZAP technique requires that the recrystallization process be controlled by passing unrecrystallized material, with suitable starting structure, through a steep temperature gradient at a controlled rate. In order to achieve this experimentally, a heat sourcc was positioncd as closc as possible to a heat sink, and the specimen was passed in a longitudinal direction from the heat sink into the heat source. Under the proper condition, new grains were formed initially in the hot zone and grew in an opposite direction to the motion of the specimen. The first grains to form were relatively equiaxed but the steep temperature gradient suppressed nucleation of new grains and encouraged growth competition among existing grains. Those grains with the highest boundary mobility grew at the expense of those with less mobile boundaries. As the specimen traversed the gradient, the grain size increased to a maximum size which depended not only on the structure of the starting material, but also on several ZAP process parameters. These included steepness of the temperature gradient, rate of movement of the specimen, and orientation with respect to the working direction. The transition region from equiaxed to elongated grains in sheet specimen was normally $1 / 4 \mathrm{in.}-1 / 2 \mathrm{in}$. in length and may be seen in Figure 4.

A schematic of the equipment used to produce this structure is shown in Figure 5 , where the three principal parts of the apparatus may be seen quite distinctly. These include: (1) heat source - a flat induction coil; (2) heat sink - a water cooled cu chill block; (3) specimen motion control - in this case a variable speed motor was used to drive a gear train which translated rotational motion to lateral motion. Lateral speeds achievable varied from $.01 \mathrm{in.} / \mathrm{hr}$. to $150 \mathrm{in./hr}$. Also shown in the schematic is an insulator which prevented arcing between the coil and the chill block. The specimen hot zone is shown as the shaded region immediately adjacent to the induction coil. The atmosphere surrounding the hot zone was flowing argon (commercial grade) which was contained by a quartz tube. The $450 \mathrm{KCPS} / 10 \mathrm{KW}$ power supply was controlled by an Ircon optical temperature monitor and control and an optical pyrometer was used for temperature measurements.

In addition to the component combinations shown in Figure 5 , other combinations of heat source and heat sink were used. These included a "radiation" heat source and an air impingement heat sink. The various combinations of heat source/heat sink investigated and the maximum temperature gradient achievable in each case are given in Table II. As may be seen, the steepest temperature gradient (4600F/in.) was achicved using induction heating and air impingement cooling.

TABLE II

VARIOUS COMBINATIONS OF HEAT SOURCE/HEAT SINK USED TO ACHIEVED GRADIENTS FOR THE ZAP PROCESS

Heat Source

Induction

Radiation

Induction

Induction

Radiation
Heat Sink

$\mathrm{H}_{2} \mathrm{O}$ Cooled $\mathrm{Cu}$

$\mathrm{H}_{2} \mathrm{O}$ Cooled $\mathrm{Cu}$

Ambient Air

Air Impingement

Air Impingement
Max.

$\frac{\text { Gradicnt, }{ }^{\circ} \text { F/Inch }}{3750}$ -


THE INFLUENCE OF START ING MATER IAL ON ZAP PROCESS ING

The maximum rate at which the ZAP process formed the desired large elongated grains was found to be strongly dependent on starting material. In sheet, for example, the ZAP process resulled in only inoderate increases in grain sizes. These improvements were only possible at very low ZAP rates (less than $1 / 4 \mathrm{in./hr}$.). In round bar extrusions, on the other hand, very large columnar grains were formed even at rates as high as 48 inches/hr. By comparison, high speed directional solidification is conducted at $9-12$ inches/hr. (E).

The reason for the difference in rates between round bar and sheet is not immediately apparent but examination of differences in starting substructure, working temperature and recrystallization temperature provides a reasonable explanation. Working tempcrature of the two products was quitc differcnt (Table I). Sheet rolling was done at $\sim 1300 F$ while the round bar was extruded at 1860F. The lower working temperature of the sheet resulted in a heavy dislocation density with only a vague outline of a cell structure. The bar was worked at 1860F, where dynamic recovery occurred, resulting in a very fine cell size with a very low free dislocation density, as was shown previously in Figure 3. One hour recrystallization temperature for the sheet was $\sim 1650 \mathrm{~F}$ while that for the bar was $\sim 2250 \mathrm{~F}$. During ZAP processing it was discovered that the ZAP interface, between large grains and as-worked material, existed at $\sim 1650 \mathrm{~F}$ in the sheet but at $>2250 \mathrm{~F}$ for the bar. Since it is the mobility of this intorface which is of importance to the ZAP process, highcr intcrfacc tompcraturcs should yield higher rates, as was observed. These observations would also predict that the working temperature might be very important in controlling starting microstructure, which in turn controls the ZAP process response of a given alloy. Jonas( ( ) reports not only temperature but also strain rate as primary deformation variables governing as-worked cell size.

Starting material varied considerably in spite of the fact that nominal chemistries were the same and all were produced by Fansteel with similar $\mathrm{ThO}_{2}$ size and volume pcrccnt. The principal diffcrences wcro in rccrystallization rosponse and wore the result of different working temperatures, strain rates, and deformation symmetries. As may be seen in Figure 6, which is a schematic of the various specimen and their respcinse to the ZAP process, the round bar extrusions formed "pie-shaped" grains during ZAP processing, indicating that nucleation took place near the surface. Since these were bare extrusions and since die markings were still visible after zAP processing, it was not surprising that the recrystallized structure reflects the same cylindrical symmetry as the deformation process. This symmetry was not seen in specimens cut from sheet bar since the sheet bar did not have a cylindrical deformation symmetry. Grain structure in the sheet also reflected the deformation symmetry and elongated pancake shaped grains formed, both by ZAP processing, and by normal heat treatment. In specimens cut from the airfoil leading and trailing edges, the influence of deformation symmetry was not apparent.

The degree of anisotropy in grain boundary mobility in these materials is indicated not only by their irregular grain shapes, but also by the directionality of ZAP response in specimen cut from shcct bar TC3583 with differing orientations. Maximum achievable ZAP rates were found to vary from $>48$ inches/hr. in the extrusion direction (direction A of Figure 6) to $<.5$ inches/hr. in the short transverse direction (direction C). Specimen $C$ of Figure 6 responded in a dramatically different manner to ZAP processing than did Specimens A or B. Typical response in Specimens A and $B$ was the formation of large columnar crystals. Many of these crystals were contj.nuous from one end of the six inch long specimen to the other. A cross section of one of these $1 / 4^{\prime \prime}$ diameter specimen normally contained from 1 to 3 grains, 
depending on ZAP parameters used. In the short transverse specimen (C), processed at the very low rate of $1 / 2 \mathrm{inch} / \mathrm{hr}$., the cross section of the specimen also contained 1-3 grains, but in this case, the length of the grains was small; in fact, 1/d was approximately one, as is shown schematically in Figure 6.

Both bar and sheet contained little or no deformation texture, but after recrystallizing, either by ZAP or by standard heat treatment, both alloys contained a strong recrystallization texture. This may be seen in Figure 7 , where orientation of crystals determined individually by Laue back reflection techniques is plotted on the unit stereographic triangle. Sheet specimen contain a strong $(100)<100\rangle$ orientation while bar specimen have a <lo0> riber texture. ZAP processing apparently did not influence the intensity of this texture.

\section{THE INFLUENCE OF ZAP RATE ON MICROSTRUCTURE AND PROPERTIES}

Increasing the rate of specimen movement through the temperature gradient decreased grain size of the resulting product as may be seen in Figure 8 for TD NiCr sheet. Grain size in this figure is taken as the area, $L \times W$, where $L$ is length and $W$ is width of the grain. Grain thickness was much smaller than both $L$ and W. A schematic diagram of the influence of ZAP rate on microstructure of extruded round bar is shown in Figure 9. As may be seen here, changes are quite subtle in the range from 12 to 48 inches/hr. but the material prepared at 144 inches/hr. had a much smaller, less elongated grain structure. The influence of ZAP rate on $2000 \mathrm{~F}$ stress rupture properties is shown in Figure 10 for sheet, round bar, and airfoil extrusions. The ordinate in Figure 10 is rupture stress necessary to cause failure at 10 hours, and was obtained by plotting the actual data on a Larsen Miller parameter plot (C = 25) and extrapolating to a parameter of 64 using the same slope as is observed in standard TD NiCr sheet. As may be seen in Figure 10 all three mill forms were strengthened appreciably by the 7AP process, with the maximum strength varying from about $14.5 \mathrm{ksi}$ to $16.5 \mathrm{ksi}$ depending on the starting material. The grain size in the airfoil specimen ZAP processed at 5 inches/hr. was very large and the gage length contained only two or three grains with no transverse grain boundaries. As is shown in Figure 9, the extruded round bar had pie-shaped grains that did not vary appreciably in size at rates less than 48 inches/hr. Sheet bar extrusion are not shown here since only limited quantities of material were available and no systematic study of rates was conducted. At low rates, however, $1 / 4$ in. diameter specimens containing ono, two, or three grains in the cross-section were observed. These specimens had properties comparable to the best extruded airfoil specimen. Sheet data generated from specimen cut from TC3085-1 after the conventional heat treatment is also shown in Figure 10 for comparison to ZAP processed sheet. Specimens from the round bar extrusion TC2758-1 were tested after a standard $2400 \mathrm{~F} / 2 \mathrm{hr}$. heat treatment and this data is also shown in Figure 10.

Grain size measurements in ZAP processed 1/4 in. bars were very difficult since grain lengths were commonly larger than the length of the stress-rupture specimen used to evaluate properties. The following generalities may be made, however: (1) the largest grain sizes were achieved in $1 / 4 \mathrm{in}$. diameter bar cut from larger sections. In these specimens, grain size (cross-sectional area) increased with decreasing ZAP rates and, at slow rates, monocrystals were observed; (2) in extruded round bars, grains were always pie-shaped, reflecting the cylindrical symmetry of the deformation process. Grain size was relatively insensitive to rates except at very high rates. Bi-crystals and tri-crystals were never observed. As a matter of fact, at low rates (< 12 inches/hr.) a fine grained outer shell was observed as is illustrated in Figure 9. This structure was found to have a $<110>$ rather than the $\langle 100\rangle$ found in the center grains. As in the airfoil and sheet bar specimens, grain length was very difficult to measure and no documentation of it has been made to date. 
A11 of the extruded products yielded a much larger grain size than did the sheet. The fact that sheet specimens, with grains only $1 / 5-1 / 10$ the size of those in extruded products, were nearly as strong, is not completely understood. As was shown previously, there were several differences between sheet and bar. These include: (1) different recrystallization textures. Sheet specimen had a (100) [100] sheet toxturo whilo $1 / 1$ in. diameter bar specimen had a [100] fiber texture; (2) grain shape was also different. Sheet contained elongated pancake shaped grains with two large dimensions and a third dimension which was much smaller. In the extruded products, the grains were relatively equiaxed in the transverse cross section and these two dimensions were much smaller than the third; (3) many of the boundaries had a highly irregular shape giving rise to a mechanical interlocking effect akin to that in a jig-saw puzzle. This was very difficult to measure quantitatively, but it seemed to be more pronounced in the sheet; (4) the final difforcncc rosultcd from differences in total strain experienced by the various mill forms and was related to degree of homogeneity of the $\mathrm{Cr}_{2} \mathrm{O}_{3}$ inclusions. In sheet which received more total reduction than the extruded products, the $\mathrm{Cr}_{2} \mathrm{O}_{3}$ was smaller and had a better spatial distribution. Thus, these small $\mathrm{Cr}_{2} \mathrm{O}_{3}$ particles may have been less effective as stress concentrators in sheet and more effective barriers to dislocation motion, both of which could enhance properties.

All of the materials processed by the ZAP technique were examined by electron transmission microscopy. In all cases the material was characterized by very low densities of free dislocations, a high frequency of annealing twins, and a $\mathrm{ThO}_{2}$ size distribution which was essentially unchanged from that observed in material given the conventional recrystallization heat treatment. These features may be observed in the transmission photographs of Figure 11 .

\section{THE INFLUENCE OF TEMPERATURE GRADIENT ON MICROSTRUCTURE AND PROPERTIES}

Two separate techniques were used to vary the steepness of the temperature gradient along the length of the bar. In the first, different combinations of heat sources/ heat sinks were used as were listed in Table II. The second technique was used principally with the induction heating/water cooled Cu chill block combination of Figure 5. In this case, the separation between heat sink and heat source was varied which resulted in variations in temperature gradient. Specimens prepared at 24 inches/ hr. using $1 / 8$ and $1 / 4$ in. separations between the induction coil and the $\mathrm{H}_{2} \mathrm{O}$ cooled $\mathrm{Cu}$ chill. block were stress-rupture tested at 1800,2000 and 2200F. A Larsen-Miller parameter plot of this data is shown in Figure 12 where the material prepared with the $1 / 8$ inch spacer (2450F/in.) appears to be at least two parameters better than that prepared with the $1 / 4$ in. spacer $(3750 /$ in.).

When the gradient was altered by changing heat source from induction to radiation, the maximum rate at which columnar grains were formed in TC3758-1 decreased by almost an order of magnitude. This change effected a decrease in gradient from 3750 to $2400 \mathrm{~F} / \mathrm{i}$. and a corresponding decrease in maximum rate from $>48$ inchcs/hr. to $\sim 6$ inches/h.r.

\section{Discussion}

Transverse grain boundaries are a source of weakness in the high temperature properties of TD NiCr. As a result, increases in grain size and/or grain length to diameter ratio causes a corresponding increase in $2000 \mathrm{~F}$ stress rupture propertics. The ZAP process produces larger and more elongated grains in the mill forms investigated than those achleved by standard heat treatments and thereby enhanced stress rupture properties. ZAP processing of small diameter bar for example, increased $2000 \mathrm{~F} / 10 \mathrm{hr}$. rupture stress by more than a factor of two over that obtained by standard 
recrystallization heat treatments. In addition, rupture ductility was also higher after ZAP processing; $i$. e., both sheet bar and round bar had rupture elongation in the range from $7-12 \%$ in comparison to $1-3 \%$ elongations from similar specimen given the standard heat treatment.

The maximum rate of specimen motion at which columnar structure was achieved was found to depend both on material processing history and ZAP parameters. Recrystallization temperature was the most important variable associated with the starting material, and low recrystallization temperature caused the maximum ZAP rate to be very low. Maximum rate is thought to be controlled by the mobility of the interface between recrystallized and as-worked material. Boundary mobility is strongly temperature dependent and in the round bar, where the interface temperature was $>2250 \%$, mobility was $>48$ inches $/ \mathrm{hr}$. In sheet where the interface temperalure was $\sim 1650 \mathrm{~F}$, the boundary mobility was less than $0.25 \mathrm{inch} / \mathrm{hr}$.

Severity of temperature gradient was also found to play an important role in ZAP processing. Maximum achievable rates in as-extruded round bar decreased when the gradient was decreased.

Evaluation of as-processed material showed that ZAP processing did not appreciably change the $\mathrm{ThO}_{2}$ size. Dislocation density was very low and large numbers of annealing twins and a strong (100) recrystallization texture were found after ZAP processing. In the sheet bar, a recrystallization texture was formed in spite of the fact that the material contained no deformation texture. Metal working did produce anisotropy in the material, however, and $\mathrm{Cr}_{2} \mathrm{O}_{3}$ size and spatial distribution were found to be strongly influenced by the extent and direction of plastic deformation used to fabricate the shapes investigated. Grain boundary mobility was also found to be highly anisotropic and for sheet bar, was found to vary by more than an order of magnitude with variations in direction. 'This anisotropy is undoubtedly the reason that TD NiCr sheet recrystallizes to pancake shaped grains during conventional heat treatment. Since this elongated structurc cnhances stress rupture properties, it is obvious that control of the recrystallization process is vital to the production of material with good high temperature properties.

The mechanism by which a large elongated textured grain structure is produced from a randomly oriented as-worked structure is uncertain but two factors are postulated to be governing: (1) it has been reported previously(8), that boundary mobility is a function of the orientation of the boundary with respect to the crystallographic orientation of the growing grain and; (2) grain boundary mobility was shown here to be strongly dependent upon non-crystallographic anisotropies such as those seen in the distribution of $\mathrm{Cr}_{2} \mathrm{O}_{3}$ particles. It is postulated that the combination of these two effects yields not only irregularly shaped grains, but a recrystallization texture as we11. Thus only those nucleii that are oriented so that the crystallographic "fast growth direction" coincides with the direction which has the lowest density of grain boundary pixuing agents will have highly mobile boundaries. The <001 $>$ is evidently a fast growth direction in $\mathrm{TD} \mathrm{NiCr}$ but in sheet for example, layering of the $\mathrm{Cr}_{2} \mathrm{O}_{3}$ particles produces such formidible barriers to boundary mobility that growth in the thickness direction is low in spite of the fact that it is the <001> direction. As a result, pancake shaped grains form in which thickness is much smaller than length or width.

\section{Summary}

When grain size and $1 / d$ were increased simultaneously by ZAP processing, rupture strengths of TD NiCr were shown to increase dramatically. Rupture strengths as high as $16.5 \mathrm{ksi}$ for 10 hour 1 ife at $2000 \mathrm{~F}$ were achieved in such structures. Columnar 
or monocrystalline grain structures were successfully produced in specimen prepared from four separate mill forms; sheet, .235" diameter extruded bar, $1^{\prime \prime} \times 6^{\prime \prime}$ extruded sheet bar and an airfoil shaped extrusion. ZAP rates as high as 48 " per hour were successfully conducted. These rates are high enough to make the process of practical interest. Microstructures achieved by the ZAP process were found to be dependent upon both the metal working history of the specimen and several ZAP process parameters. The most important of these were severity of the temperature gradient, and rate of specimen movement through the gradient.

A maximum rate of travel was observed, above which, columnar grains were no longer formed. This maximum rate varied widely with varying metal working history and decreased with decreasing temperature gradient.

The ZAP process appears to have sufficient potential to warrant scale-up for the manufacture of hardware. Two advantages are expected from the application of ZAP processing to $\mathrm{TD} \mathrm{NiCr}$ parts: (1) utilization of low cost extrusions as input material, thus eliminating costly TMP processing and; (2) improved part performance as a result of increased properties. 


\section{$\underline{\text { References }}$}

1. B. A. Wilcox and A. H. Caluer - Trans. AIME, 1966, Vol. 236, p. 570.

2. B. A. W11cox and A. H. Clauer - Final Report NASA Contract NAS3-1167, NASA $\mathrm{CR}-72832$, March, 1971.

3. A。 L. Mincher and J。S. Clark - 6th Interim Progress Report, AF Contract No. AF33 (615)-1680, October, 1966.

4. R. E. Allen - Final Report Naval Air Systems Contract No. 00019-70-C-0232, January, 1970 .

5. R. W. Traser and D. J。 I. Evans, Oxide Dispersion Strengthening, GS Ansell, et al, Eds., Gordon and Breach, NY 1968, p. 375.

6. J。S, Erickson, W。A. Owczarski and P. M. Curran, Metal Progress, March, 1971, p. 58 .

7. J. J. Jonas, Co Mo Sellars and W。 Jo McG. Teagart - Met. Reviews 130, January, 1969 .

8. J. R. Brown, J.Applied Phys., 1958, Vol. 29, No. 3, p. 359 . 

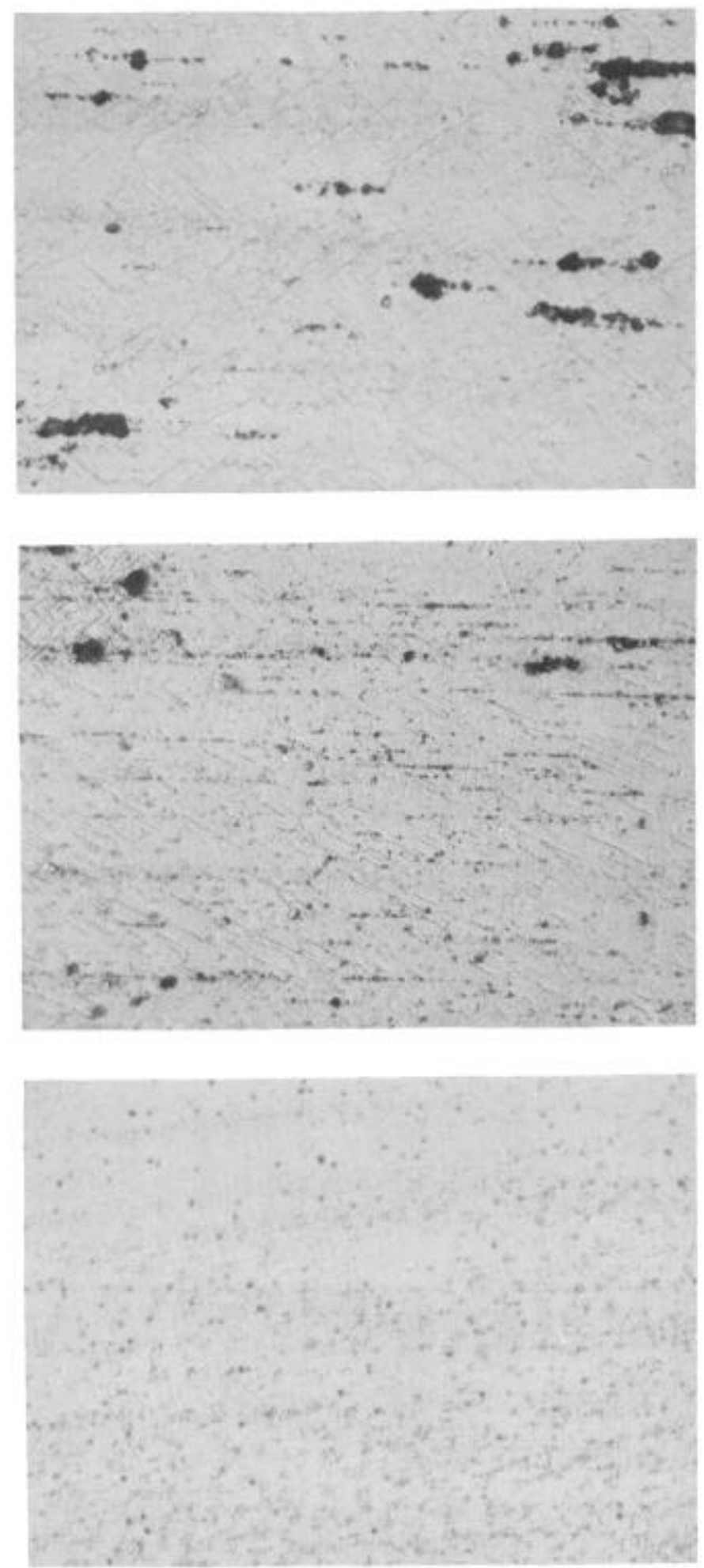

Extruded Sheet Bar TC3200

Extruded .235" Dia. Bar TC2758-1

$.060^{\prime \prime}$ Sheet

TC3085-1

FIGURE 1 Spatial Distribution of $\mathrm{Cr}_{2} \mathrm{O}_{3}$ for Three of the Four Starting Materials. Working Direction was Horizontal in Each Case. 500x Mag. 


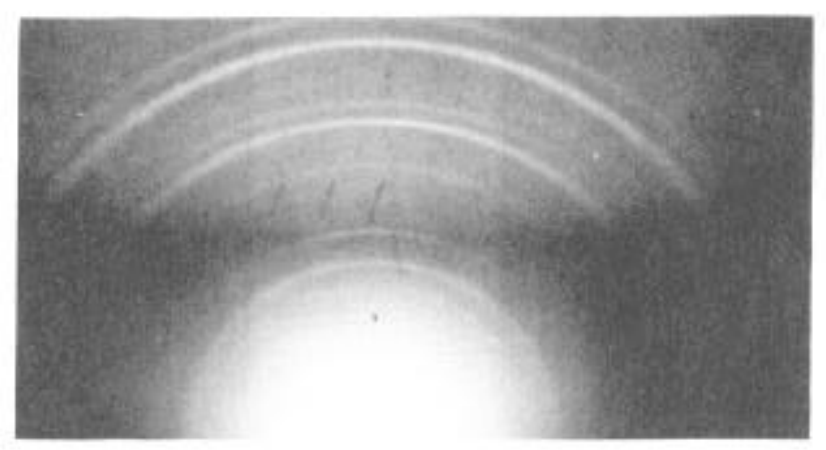

Longitud 1 nal

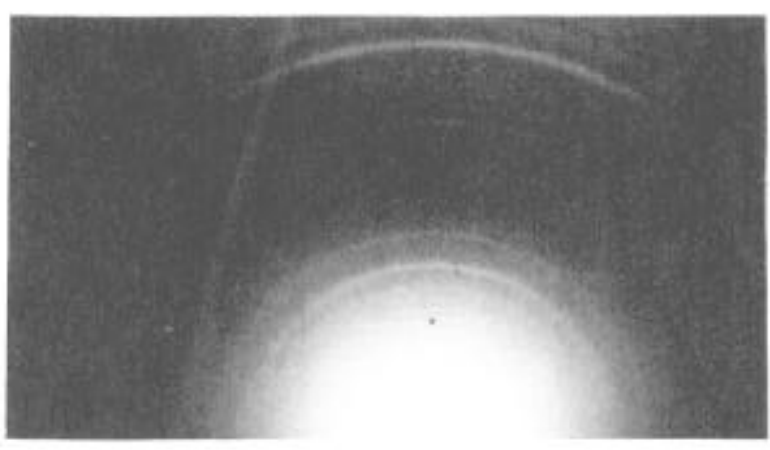

Transverse

Sheet Bar TC3200

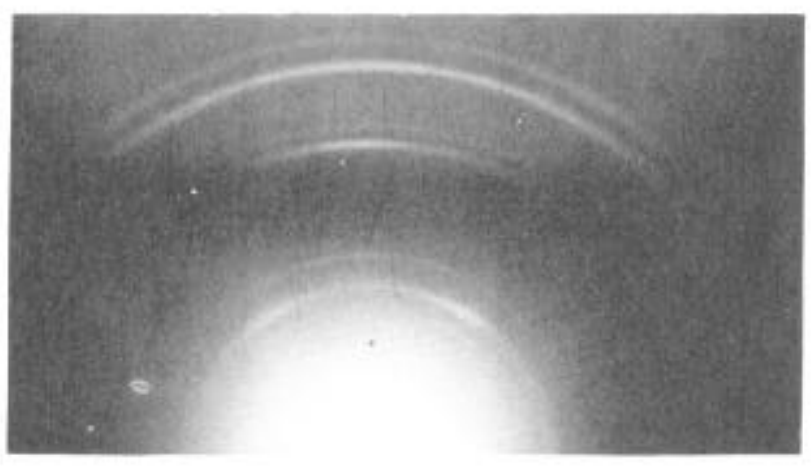

Surface

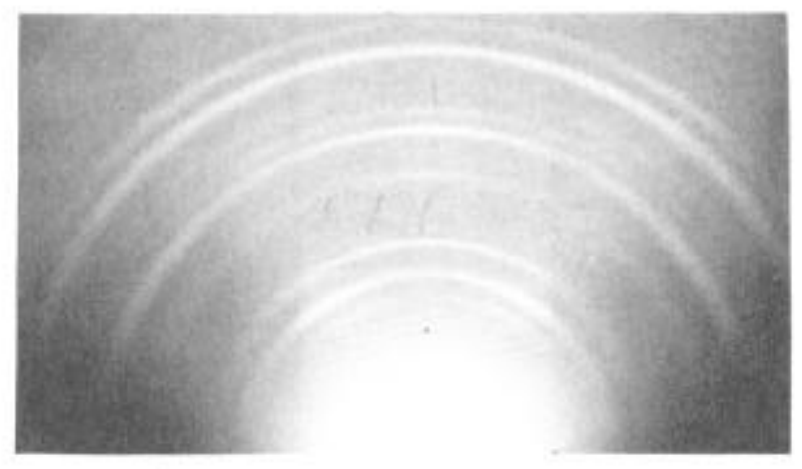

Sub-Surface

Longitudinal .235" Dia. Bar TC2758-1

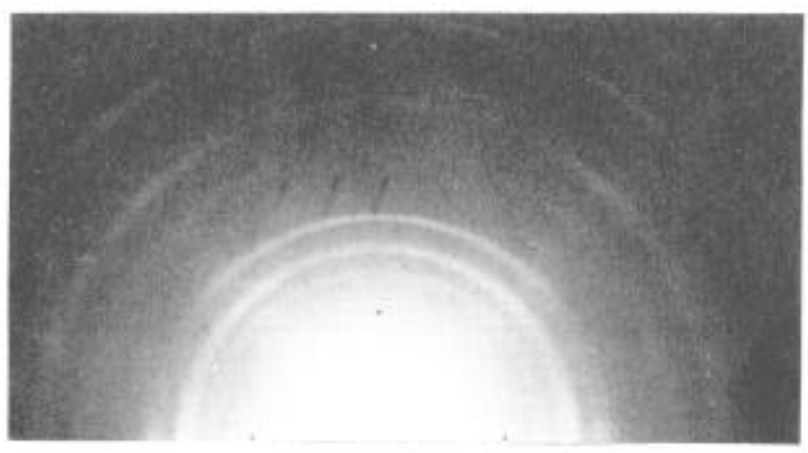

Long1 tudinal

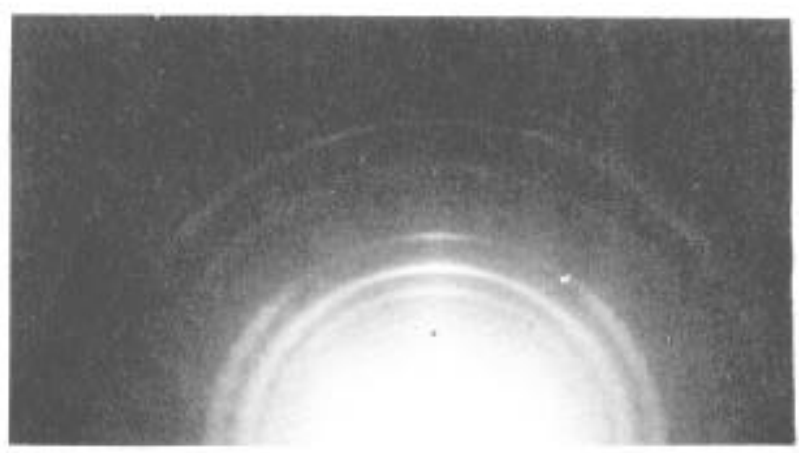

Transverse

$.050^{\prime \prime}$ Sheet TC3085-1

FIGURE 2 Laue Transmission Photographs of Three of the Four Starting Materials. 


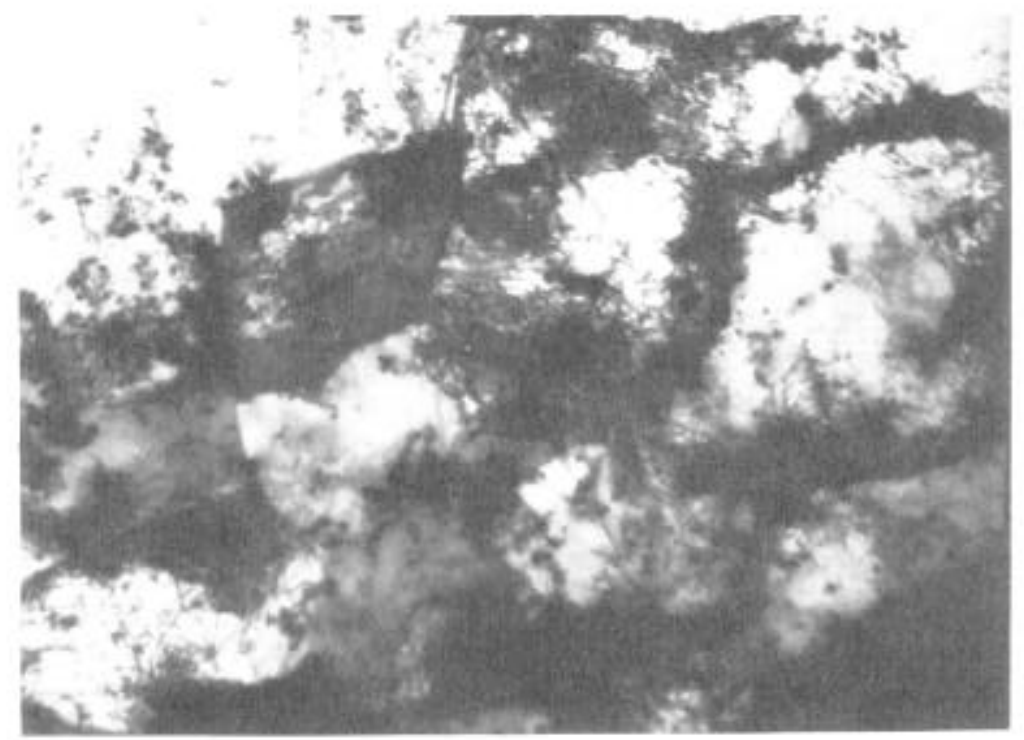

Sheet TC3085-1

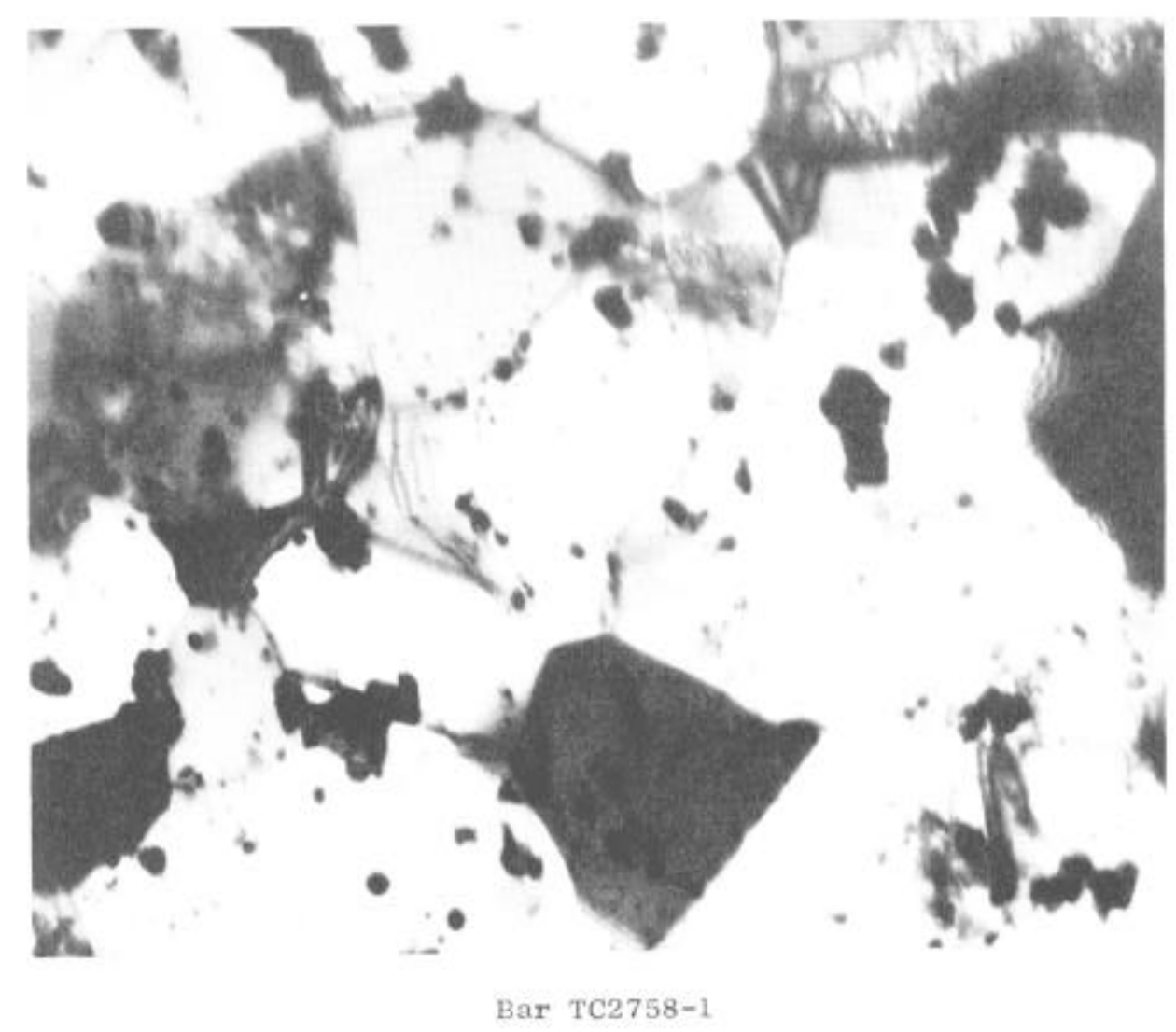

FIGURF 3 Electron Transmission Microscopy of As-Worked TD NiCr Sheot and Bar. 


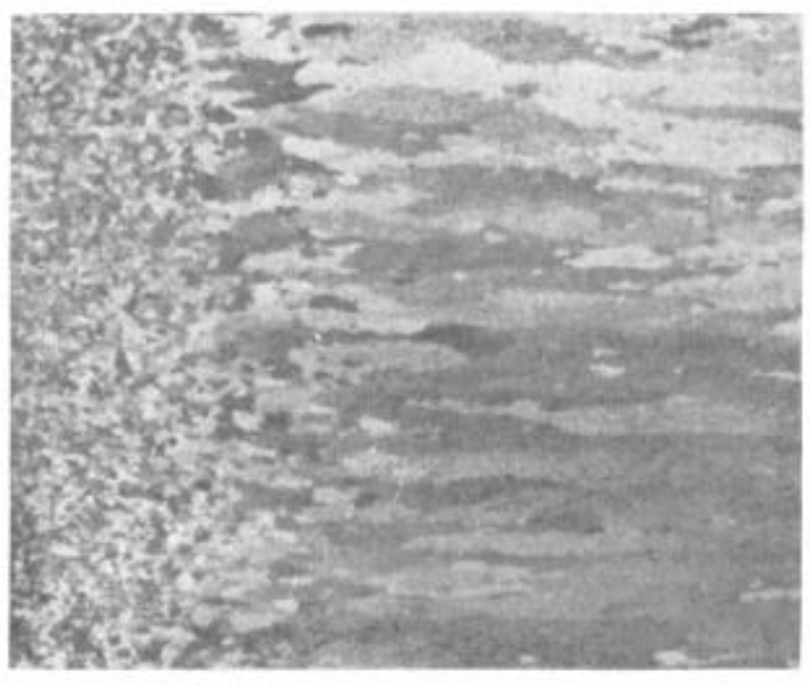

Growth Competition

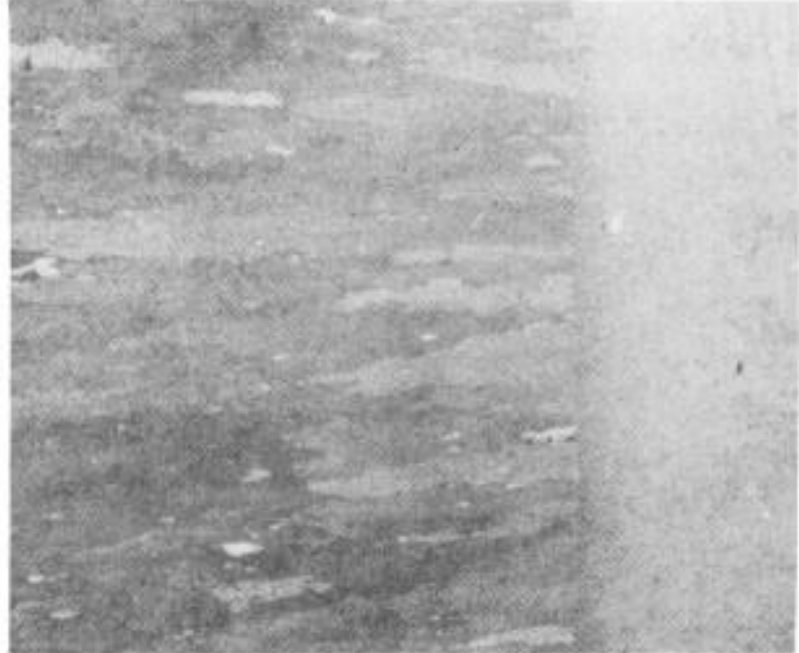

ZAP Interface

TD NiCr SHEET

F1gure 4 Macrophotograph of TDNiCr Sheet Show1ng: (a) Initial Equiaxed Gra1ns; (b) Region of Growth Compet1t1on; and (c) The ZAP Interface. Material Designation TC3085-1, Mag. 5X 


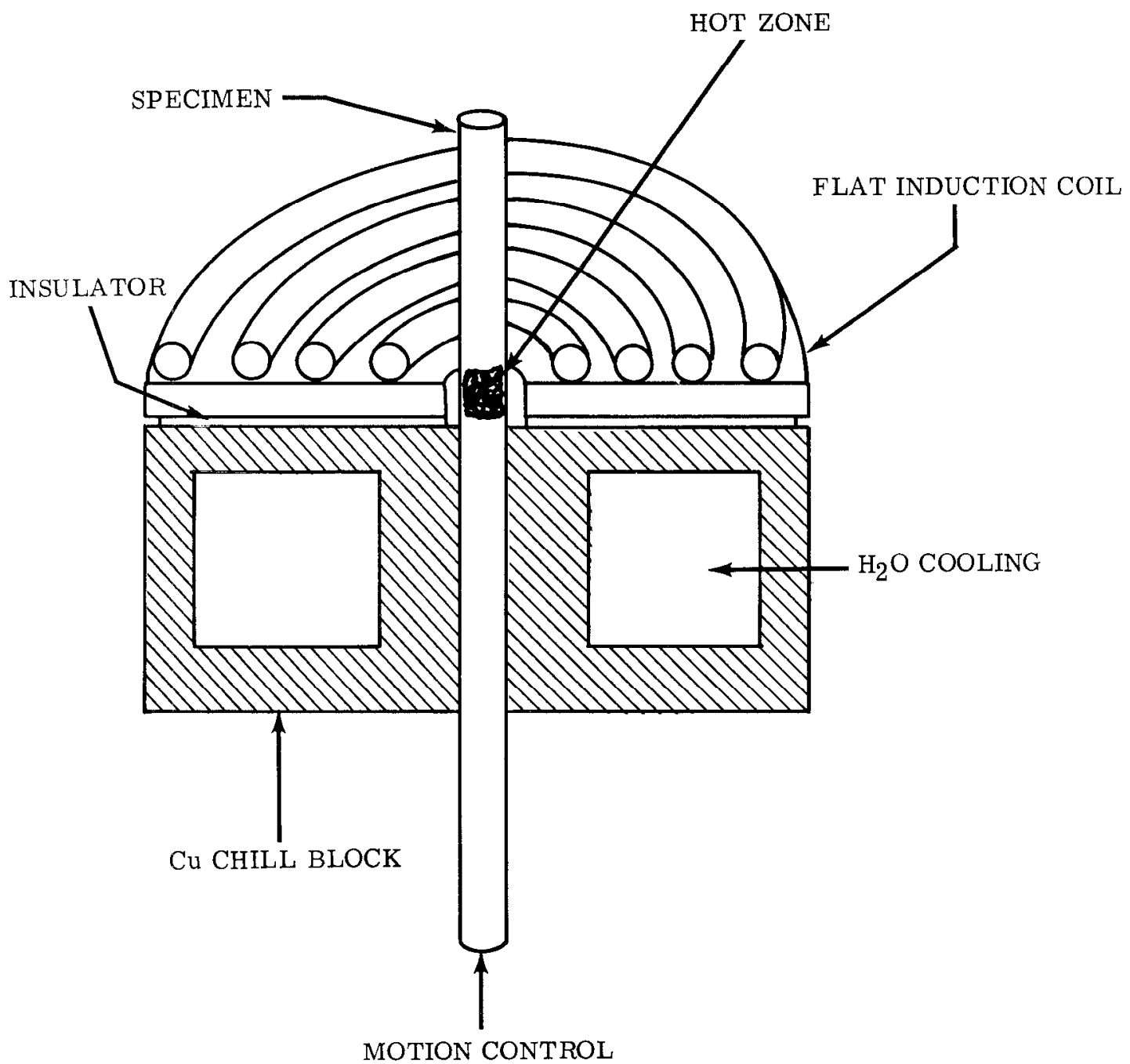

Figure 5 Schematic Diagram of Induction Coil Heat Source and Water Cooled Copper Chill Block Combinations Used to Produce Elongated Microstructures in the ZAP Process. 
1. Extruded Round Bar

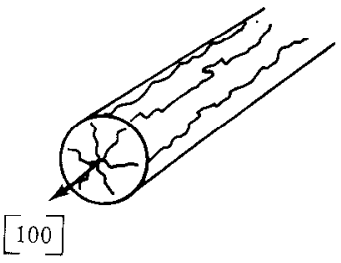

2. Extruded Sheet Bar

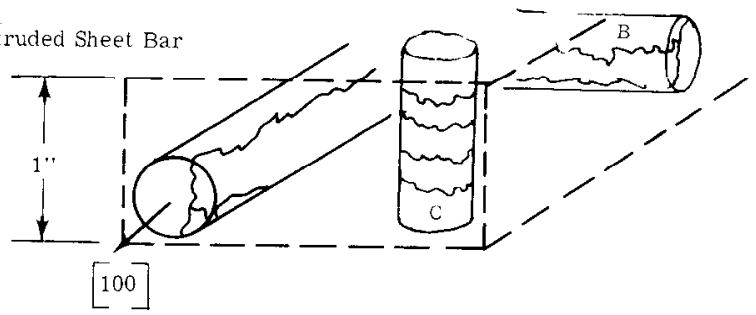

3. Sheet
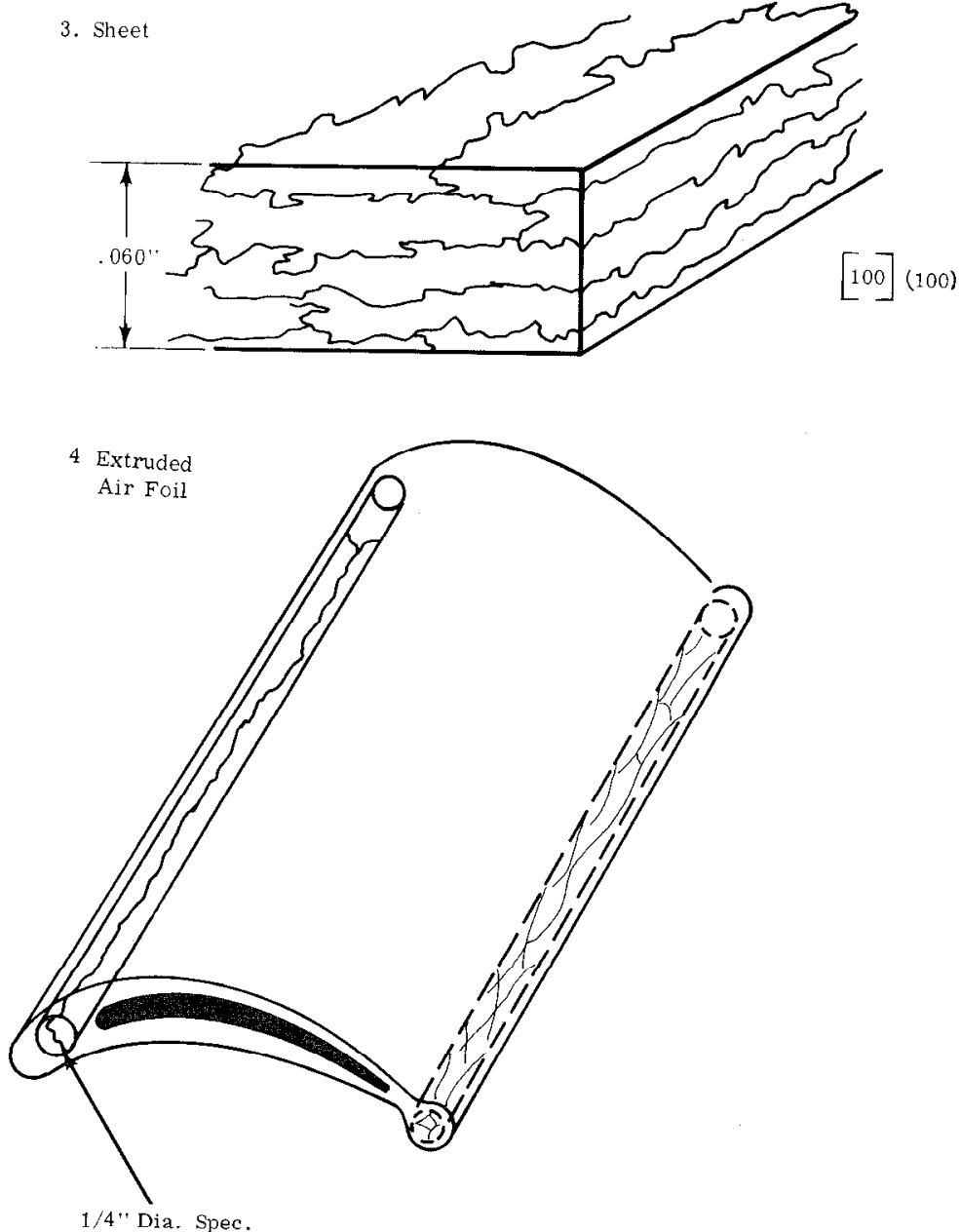

FIGURE 6 Sketches of Starting Material Used to Investigate ZAP Process Parameters. Schematic Illustration of Microstructural Response of Each Material to ZAP Prucess 1s Also Shown on Each Sketch. 

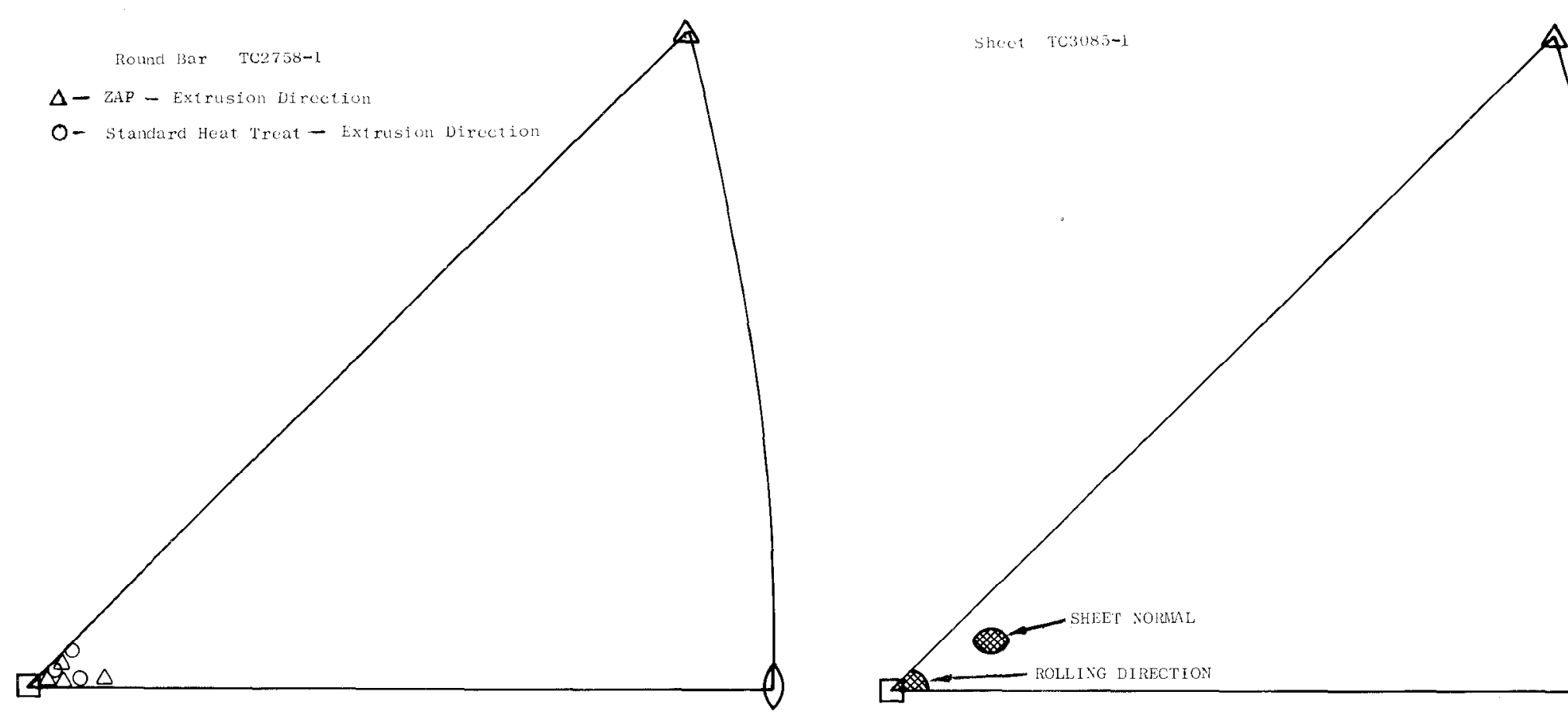

FIGURE 7 Orientation of Working Direction(s) with Respect to Crystallographic Orientation for Large Recry Grains of TD NiCr, as Determined by Laue Back Reflection Techniques. 


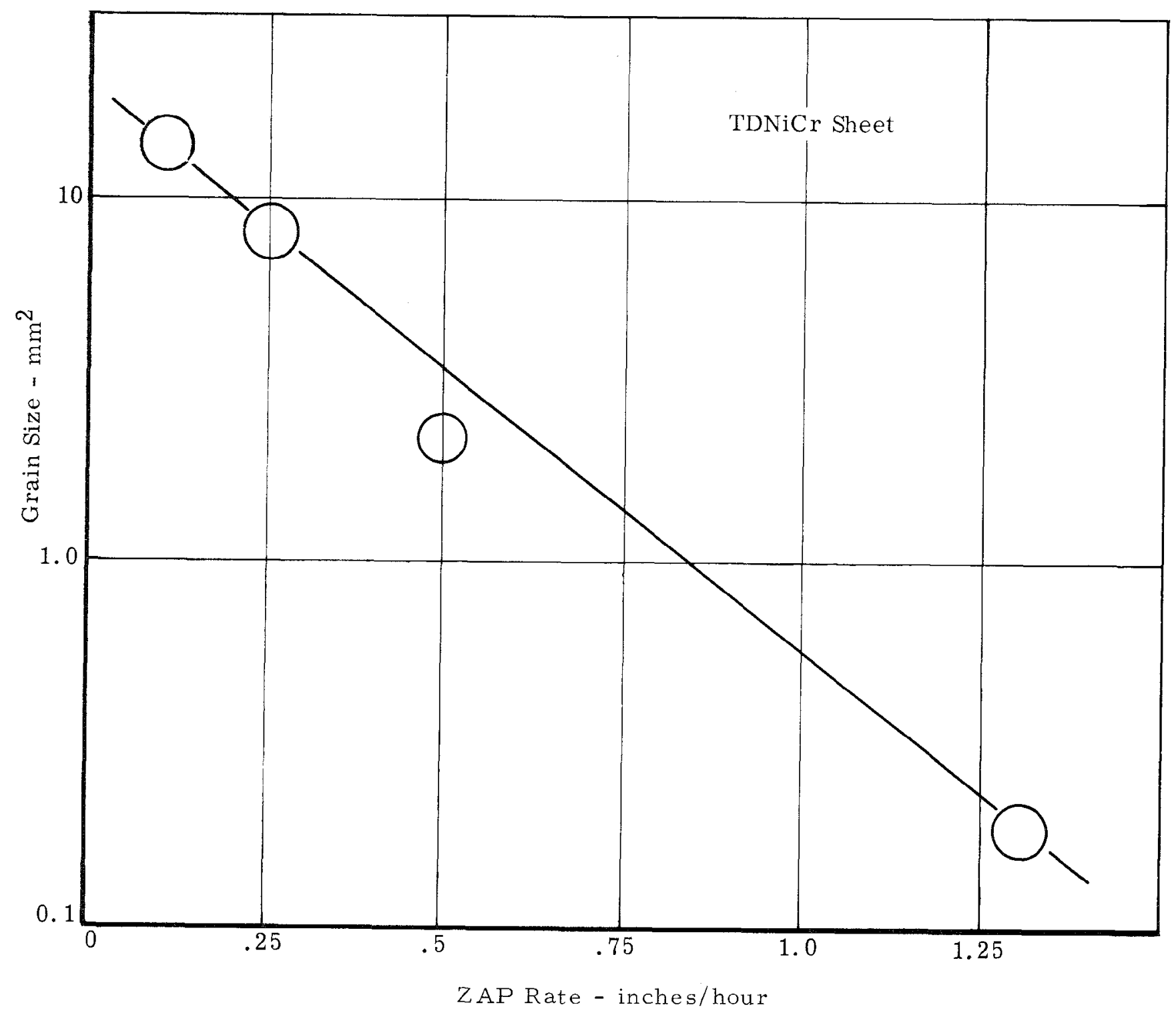

Figure 8 The Infiluence of ZAP Rate on Grain Size in TD NiCr Sheet TC3085-1. Grain Size is Plotted as Area, Determined as Length Times Width of Elongated Pancake Shaped Grains. 

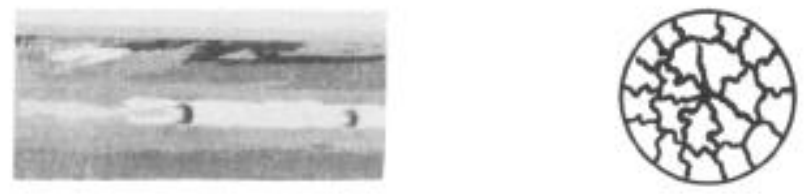

12 inches/hour
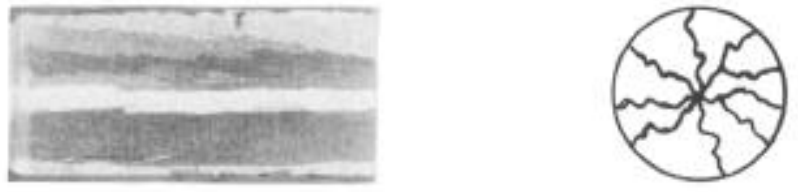

24 inches/hour
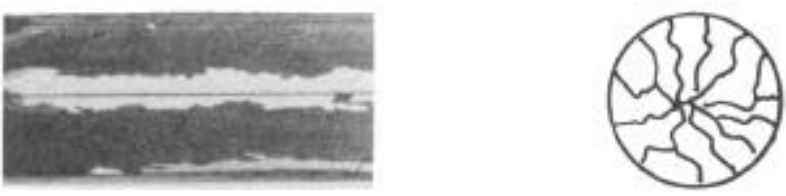

48 inches/hour
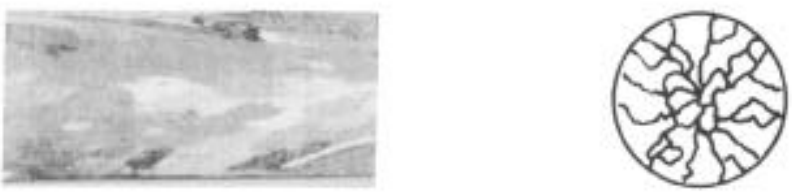

144 inches/hour

Longitudina1

Transverse

Figure 9. Microstructural Response of $\mathrm{TD} \mathrm{NiCr}$ Bar TC2758-1 to Variations in ZAP Rate. Induction Heat Source/ $\mathrm{H}_{2} \mathrm{O} \mathrm{Cool}$ Cu Heat Sink. Gradient $=3750 \mathrm{~F} /$ in. $4 \mathrm{X}$ 


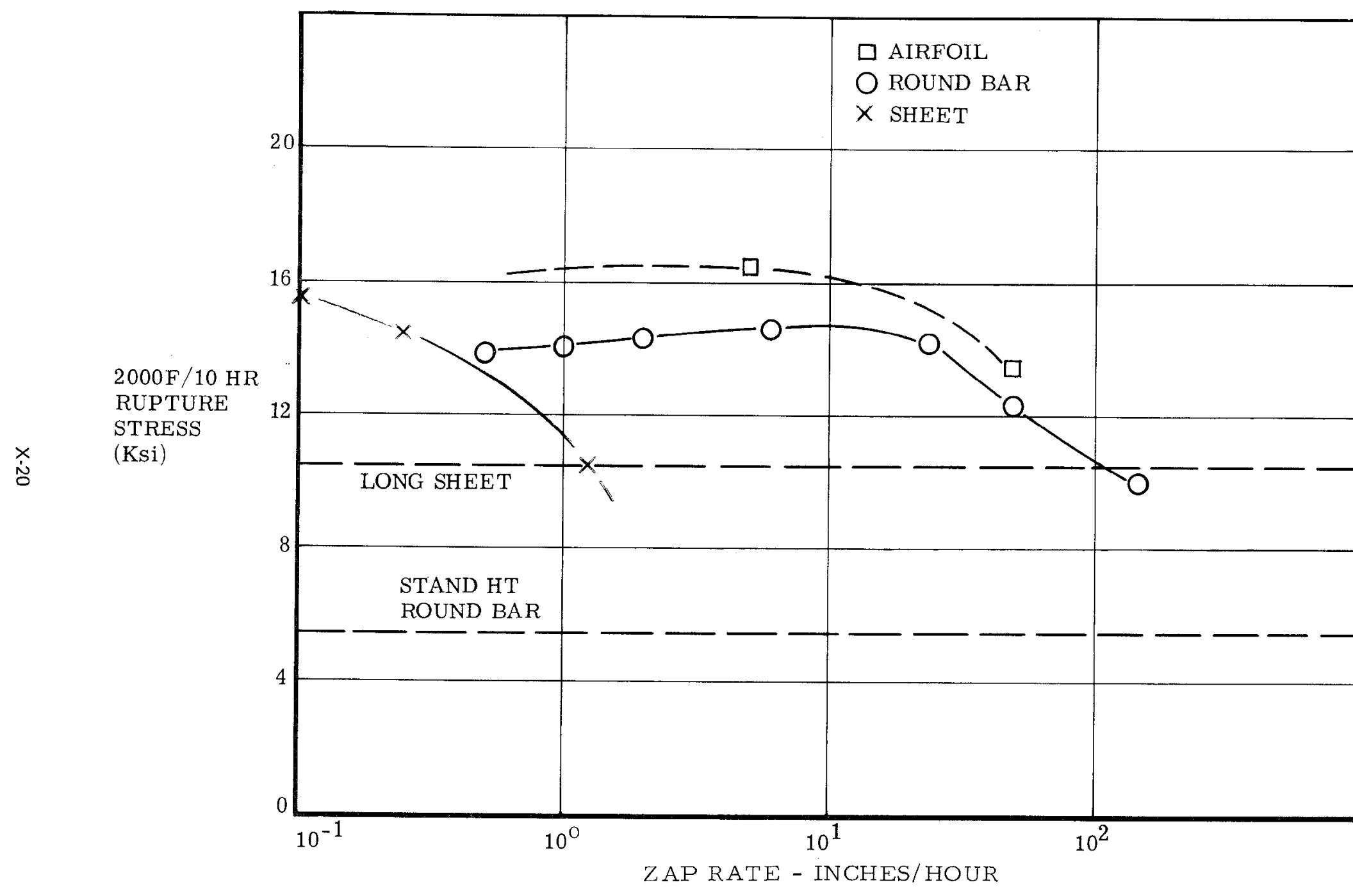

Figure 10 Stress for Rupture in $10 \mathrm{hrs.}$ Vs ZAP Rate for Three Different Mill Forms of TD NiCr; Sheet, 1/4" Round Bar Extrusions and 1/4" Diameter Specimen Cut From Airfoil Shaped Extrusions. All ZAP Prod was Done Using an Induction Heat Source $/ \mathrm{H}_{2} \mathrm{O}$ Cool Cu Heat Sink. 


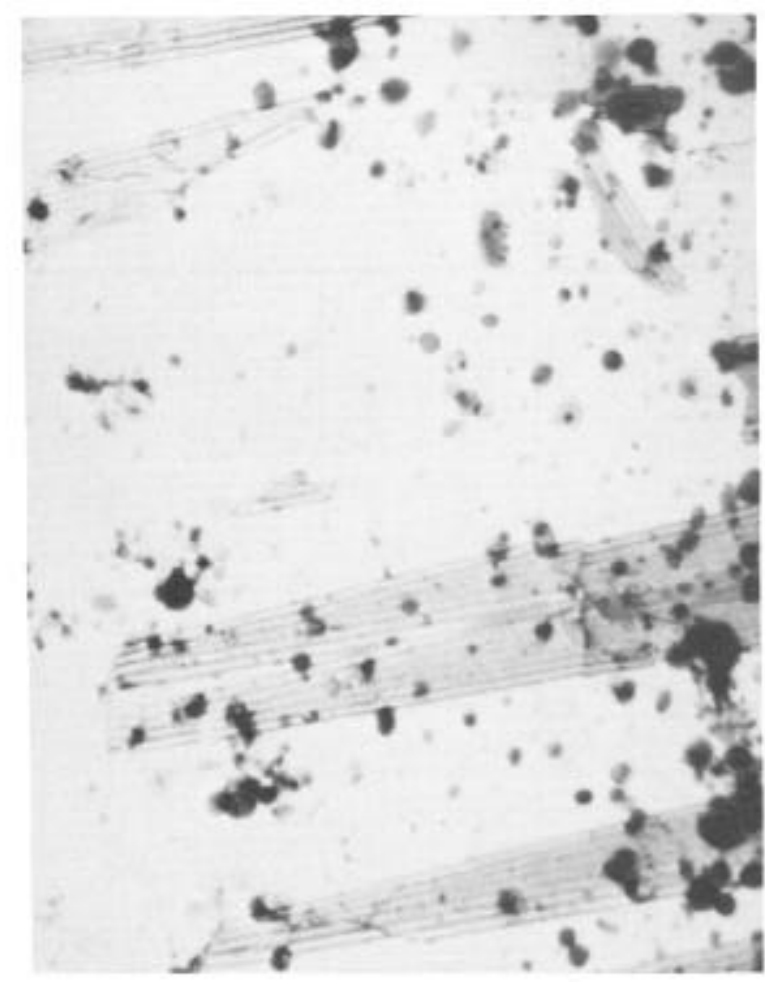

$\vdash .4 \mu-1$

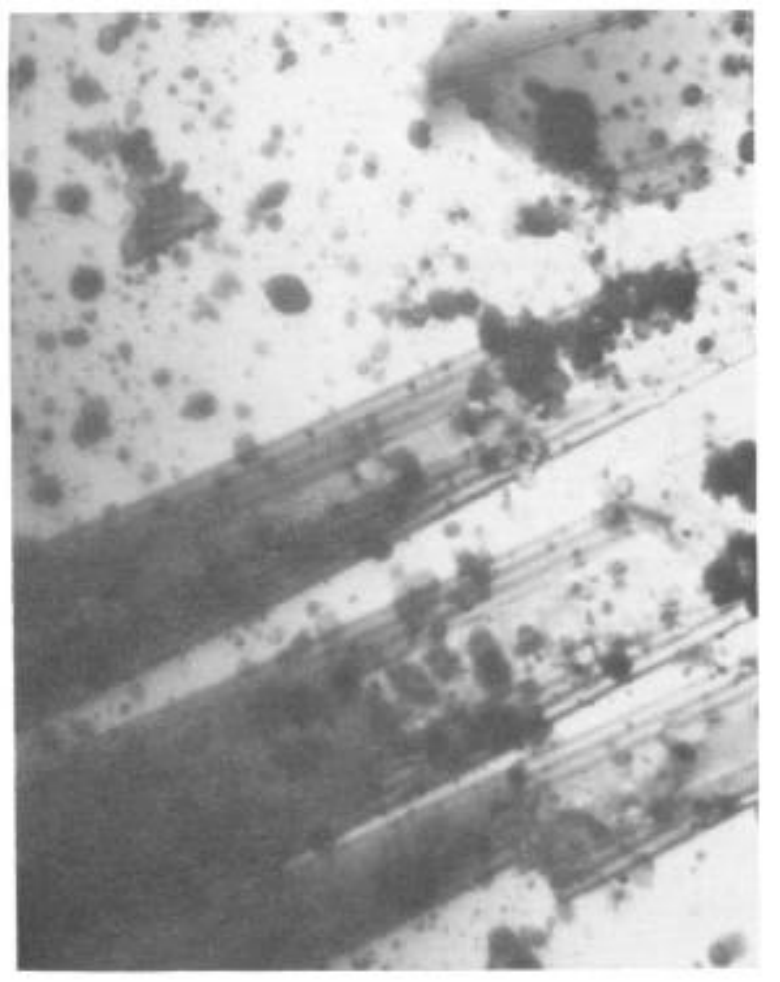

$\vdash .5 \mu-1$

Figure 11 Transmission Electron Micrograph of TD N1Cr Sheet TC3085-1 after ZAP Process1 


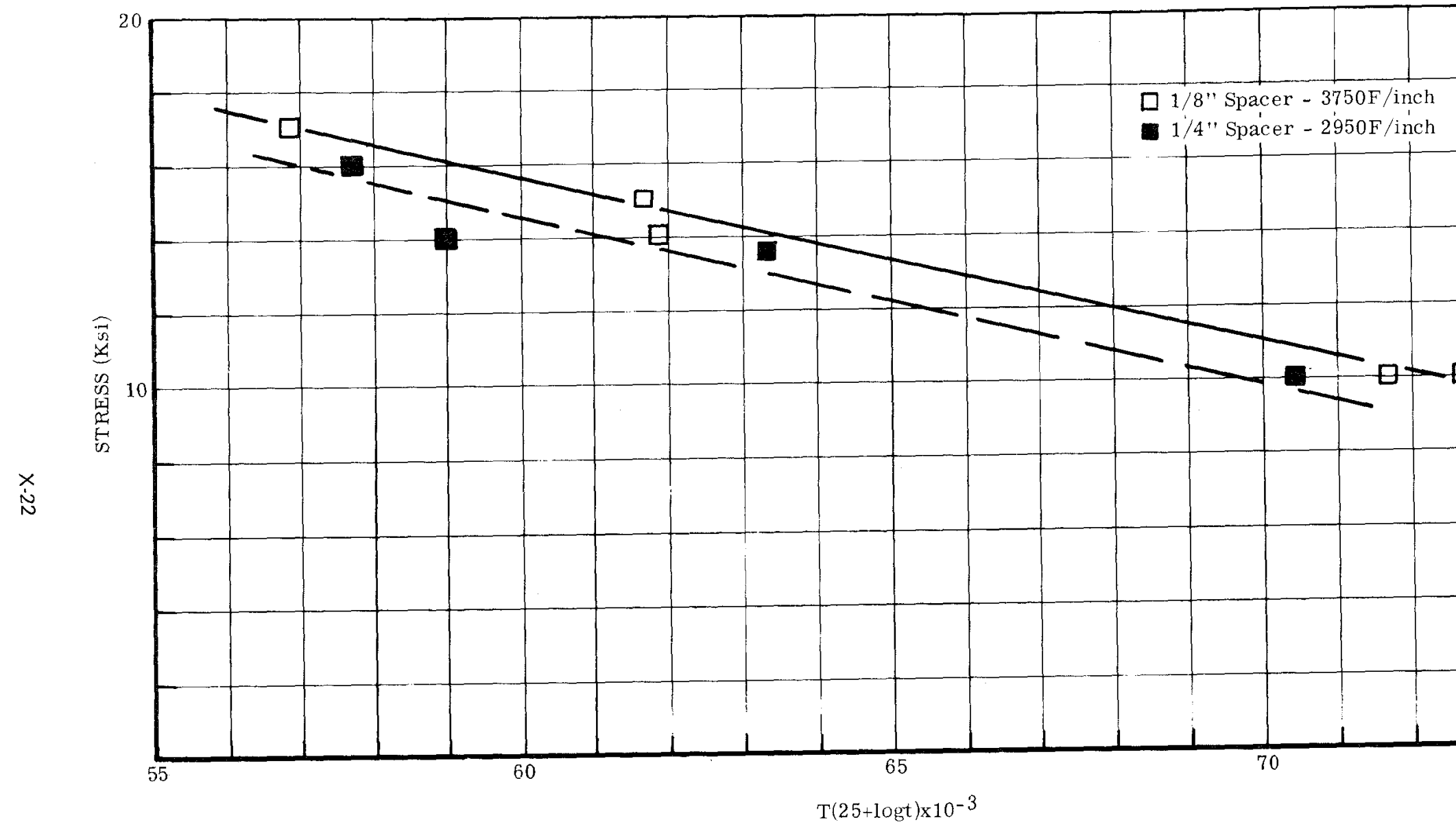

Figure 12 Influence of Temperature Gradient on Stress Rupture Properties of TD NiCr Bar TC2760-1) 